\title{
CORNEAL NEEDLE*
}

\section{A MODIFICATION}

\author{
BY \\ P. JAMESON EVANS \\ Birmingham
}

THE corneal needle recently described (Evans, 1954) has filled a need in corneal surgery and continues to give satisfactory results. The makers $\dagger$ have now suggested a modification which I find is an improvement. The new version of the noedle has the eye placed sideways, that is, in the lateral plane instead of in the same plane as the blade, and the eye is grooved as before.

It will be realized that the broadest part of the needle is the width of the cutting edge at the middle of the blade and this is the dimension of the track through which the suture must follow. Since this measurement is a maximum and substantially greater than the corresponding perpendicular dimension, the suture passes more smoothly in this track than it would in the track perpendicular to it.

In corneal grafting by edge-to-edge suture the modified needle has proved its worth, and is as robust as before, the eye standing up to compression in the needleholder without any loss of shape.

\section{REFERENCE}

Evans, P. Jameson (1954). British Journal of Ophthalmology, 38, 630.

*Received for publication November 30, 1955.

+ Messrs. Shrimpton and Fletcher, Redditch, Worcs.

The agents from whom these needles may be obtained are : Philip Harris Ltd., 144 Edmund Street, Birmingham, 3.

\section{BOOK REVIEWS}

Anesthesia in Ophthalmology. Edited by W. S. AtKInson, 1955. Charles Thomas, Illinois. Pp. 101, 44 figs. (23s. 6d.).

This is a most useful little book dealing in a thorough and balanced manner with the problems of anaesthesia as they affect ophthalmology. Pre-anaesthetic preparation is dealt with wisely and sympathetically-eliminating apprehension, testing the drugs (e.g. Nembutal) which it is proposed to use pre-operatively for sedation the day before to disclose any idiosyncrasy, and providing a quiet and orderly atmosphere. The various drugs or combinations of drugs available for pre-anaesthetic preparation are discussed; topical and block analgesia are described as well as the use of hyaluronidase as a spreading agent in retrobulbar anaesthesia. Akinesia of the orbicularis is recommended by means of a block along the inferior edge of the zygomatic bone, a technique which neither induces oedema over the lids nor involves paresis of the entire face as often occurs with a facial block attained by injection at the ramus of the mandible. The use of curare is sensibly discussed as well as the place of general anaesthesia in ocular surgery. Altogether an excellent book enlivened unexpectedly by amusingly dramatic illustrations which certainly drive home the point they purport to convey. The book is lavishly produced in a manner in which expense is obviously of no consideration. 
The Lacrimal System. Clinical Application. By Everetr T. Veirs. Pp. viii and 158, 73 half-tone illus., index. Grune and Stratten, New York and London. 1955. $(\$ 7.50 ; 52 s .6 d$.

This book presents within reasonable limits of size a conspectus of the anatomy, physiology, malfunction, and disease of the various components of the lacrimal apparatus. The chief criticisms that can be made are that it is marred in places by errors of grammatical construction, and that for radiological examinations Lipiodol should by now have been replaced by more fluid and therefore more easily manageable substitutes which have the additional advantages of exciting less reaction in the unfortunate but sometimes inevitable event of a false passage. Nevertheless, the work is clearly written and forthright, and the illustrations well chosen and excellent. As a handy guide to the ophthalmic plumber this book should be assured of a warm welcome.

Neurogenic Nystagmus (Der neurogene Nystagmus). Вy J. Онм. 1955. Рp. 134, 154 figs, bibl. Ferdinand Enke, Stuttgart. (DM 40; 70s.).

Ohm has followed up his previously published monographs on miners' nystagmus and congenital nystagmus by a further monograph on nystagmus in diseases of the central nervous system; the.book follows the lines of the other two and is a résumé and assessment of the immense amount of work which the author has devoted to this problem and published in the literature for over 40 years. His methods of measuring and recording nystagmus are fully described, as well as the characteristics of the various types of nystagmus (optokinetic, vestibular, and so on) occurring in central nervous disorders. Thereafter follows the study of $\mathbf{4 3}$ cases, indicating the types of nystagmus seen in a large range of diseases of the central nervous system, both congenital and acquired. The book finishes with an analysis of the anatomy and function of the various centres in the midbrain and vestibular system and a general summary of the author's. views on a subject in which he is an undoubted authority. It is indeed valuable to have collected and integrated in this volume the work of almost half a century, available to-day only in scattered papens in the literature.

The Cornea. By C. I. Thomas. 1955. Blackwell, London; Thomas, Springfield, Ill. Pp. 1318, 400 figs, 20 col. plates. ( $£ 10$ 15s. 0 d.)

This is the most comprehensive treatise on the cornea in health and disease in modern literature, embracing the entire field of anatomy, comparative anatomy, embryology, physiology, methods of examination, congenital anomalies, and the multitude of diseasesdystrophic, inflammatory, allergic, neoplastic, and so on-which are peculiar to this tissue itself as well as those shared by it in systemic pathological conditions. There is a long and detailed chapter on injuries, and the last quarter of the book is devoted to methods of treatment: medical, radiational, and surgical. The book is detailed and exhaustive, eminently suitable for the ophthalmic specialist; as reading for the student, the general medical practitioner, and the nurse (who are also claimed as its clientèle), it will form a very indigestible course in a banquet which surfeits most. Into its writing the author has put an immense amount of literary research as well as a rich clinical experience, and he writes with considerable judgment. On the whole the book is an excellent compilation and a distinct adjunct to our literature.

Each subject is discussed in elaborate detail and the stress put on the historical evolution of each condition adds much to the interest of the reader. The reading would have been more conservative, however, if some of the lengthy passages of quotation had been, at the least, curtailed or paraphrased. The detail in which techniques are described is also perhaps out of place. In the section on methods of diagnosis there is a full description of the history of the slit-lamp and the techniques of its use; similarly with physical methods of treatment such as iontophoresis and radiation therapy. For these it might be argued 
with some reason that the practitioner who wishes to practise such methods would be well advised to study basic text-books devoted specifically to the subject. It would have been more useful, considering the excellence of the surgical section, if fuller details were given of the methods advocated for akinesia and anaesthesia. We are simply told (p.1,105): "Alkinesia (sic) is obtained by the injection of the orbicularis either by the van Lint or the Barraquer method ".

In places the author is somewhat uncritical, relying too heavily on a particular viewpoint. In the physiology of the cornea, for example, in discussing the relative deturgescence of the cornea, although he points out opposing views, too much stress is laid on the manifestly erroneous theory advanced by Cogan and Kinsey that this property depends primarily on the relative impermeability of the limiting membranes to electrolytes. Somewhat similar criticisms could be advanced regarding the theories advocated to explain the glycolysis of the cornea and its neovascularization. Occasionally a similar lapse occurs in the clinical sections. Thus the inclusion bodies of trachoma are said to occur in the basal epithelial cells as well as in the superficial cells, and to migrate into the subepithelial tissues, there to produce follicular growth; with this most observers would not agree. Filamentary keratitis is not always looked upon as an inflammatory disease; and so on. There are also some omissions. Thus, in describing the inclusion bodies of trachoma, no mention is made of the characteristic carbohydrate matrix; and all mention of the treatment of this disease is omitted, apart from incidental references in the sections on medical and surgical treatment.

There are a number of misprints, some of them confusing concerning names: thus Hassall appears on p. 23 and Hassal on p. 24; Moore's ulcer and Morren's ulcer on the same page. The production of the book is good; the illustrations generally excellent. The practice of breaking up an illustration into a complicated and a simplified form on opposite pages is ingenious, but breaks down as in Fig. 78, where on one page a series of named pointers indicating nothing face a piece of apparatus opposite. The bibliographies are full and constitute one of the best features of the book, and the indices are unusually useful.

Radio-Diagnosis in Ophthalmology (Radiodiagnostic en ophtalmologie). By E. Hartmann and E. Gilles. 1955. Pp. 412, 497 figs. Masson, Paris. (5,000 Fr. frs; 5 guineas).

There is no doubt that the ophthalmologist has need of much specialized radiography: not only does the interpretation of complicated radiographs of the neighbouring regions come into his province - the nasal sinuses, the sella turcica, and so on-but many of the $x$-ray pictures affecting his own particular specialty-such as those of the sphenoid fissure, the optic foramen, the lacrimal canal, and, more especially, foreign bodies within the eye-, require techniques of their own which are by no means universally known. A volume which describes these without going into the vast territory of general radiography is therefore of particular value, especially since the areas of ophthalmology, because of their somewhat restricted interest, rarely receive adequate attention in general radiological text-books. This undoubted need was not met until April, 1936, when Edward Hartmann prepared a special report for the Société française d'ophtalmologie which was published as "La radiographie en ophtalmologie, atlas clinique". This volume rapidly became a classical reference, and now that it is long out of print and is no longer available, it is good that a substitute has appeared. The substitute does not retain the same character as Hartmann's original volume; the latter was primarily for the ophthalmologist who wished to interpret the radiographs presented to him, but the present volume also gives in detail the techniques employed, meeting the needs not only of the clinician but also of the technician.

The book, written by a clinician and a radiologist, is completely comprehensive for its purpose. It includes radiography of the orbit and its adnexa interpreted in the widest 
sense, including the nasal sinuses and teeth, the lacrimal passages, the globe and intraocular foreign bodies, the sellar region, and the skull and spinal cord so far as ophthalmological problems are concerned. The more specialized techniques are fully detailed, including bone-free radiography of the eye and the localization of foreign bodies (for which Porcher's method is advocated), arteriography, ventriculography, encephalography, cisternography, and phlebography. The writing is excellently clear and unencumbered by an excess of detail or by descriptions of unnecessary alternative methods; the illustrations are numerous, informative (not universal in radiographic texts), and excellently produced; a useful bibliography is appended and the indexing is good. The book is unique and indispensable, and ophthalmology is much in the debt of the authors.

\section{BOOKS RECEIVED}

Anthropological and Ophthalmological Studies of the Angmagssalik Eskimoes. By E. Skeller. 1954. Pp. 231, 21 figs, 7 plates, bibl. C. A. Reitzels Forlag, Copenhagen.

This book has been reviewed in Ophthalmic Literature (1954), 8, 851.

\section{OBITUARY}

\section{William Harold Rowe Jeremy}

W. H. R. JeRemY died very suddenly from a coronary thrombosis at his home at Pinhoe near Exeter on December 27, 1955, in his 47th year. He was the only son of the ophthalmic surgeon, the late Harold Rowe Jeremy, F.R.C.S.

After taking his M.B., B.Ch., at Cambridge, he became ophthalmic house surgeon at Bart's and subsequently house surgeon at the Royal Westminster Ophthalmic Hospital. During the second world war he served as ophthalmic specialist in the R.A.F.V.R. and took his D.O.M.S. in 1943.

In 1946 he was appointed assistant surgeon to the West of England Eye Infirmary, Exeter, and surgeon in 1948; he was also ophthalmic surgeon to the North Devon Infirmary, Barnstaple, and to the West of England Institution for the Blind in Exeter.

Jeremy was always a most conscientious and competent oculist. $\mathrm{He}$ was a perfect colleague, essentially friendly and kind-hearted, and if he had a fault it was that he was too kind, and found it almost unbearably difficult to break bad news to a patient.

The sympathy of everyone will go out to his widow, and to the three young children he leaves behind him.

\section{GeOrge Arthur Brookes}

George Arthur Brookes died on August 16, 1955; he was born at Brisbane on February 22, 1880, educated at Brisbane Grammar School, and entered the Queensland Public Service. At the age of 22 he entered the University of Sydney, where he had a brilliant career and graduated in 1907. During the first world war he served in France and England with the Australian Imperial Force. In 1920 he went abroad for post-graduate study; he gained the F.R.C.S. (England) in 1921, and then, attracted to ophthalmology, worked in London at Moorfields Eye Hospital, and in Vienna, and gained the D.O.M.S. (London) in 1923. On his return to Australia he became honorary ophthalmologist at the Royal South Sydney Hospital, St. George District Hospital, and Lidcombe Hospital. 